\title{
Unani medical tourism in India: \\ Scope, influential factors, development strategies \\ Mumtaz Rabbani ${ }^{1 *}$, Khairusy Syakirin ${ }^{1}$, Betania Kartika Muflih ${ }^{1}$
}

${ }^{1}$ I nternational Institute for Halal Research and Training (INHART), International Islamic University Malaysia (IIUM), Gombak, Selangor, Malaysia.

Abstract: India is highly prosperous in a wide network of both conventional and alternative medicinal range. The term medical tourism has become famous due to its urgent necessity and desperate requirement among medical seekers. Herbal healthcare therapies are rapidly gaining ethical significance to suffice the medical tourists' needs. This paper focuses on the amalgamation of Unani medical system with tourism. Furthermore, it identifies the components of health in Unani system along with the factors determining medical tourists to choose this therapy with both domestic and international respondents. Finally, this study concludes with elements affecting travel frequency among medical tourists and the scope of Unani medical tourism in India. Thus, striving to find the best solution to promote Unani tourism and a healthy lifestyle.

Keywords: Unani system of medicine; Pearl-Marwareed; Aquaculture practice; safety contour; sustainable strategies.

Received: 30th October 2019

Accepted: 3rd February

Published Online: 2nd March 2020

*Correspondence:

Mumtaz Rabbani, International Institute for Halal Research and Training (INHART),

International Islamic University Malaysia (IIUM), Gombak, Selangor, Malaysia; mumtazrabbani20@gmail.com

Citation: Rabbani M, Syakirin K, \&Muflih BK. Unani medical tourism in India: Scope, influential factors, development strategies. J Halal IndServ 2020; 3(Special Issue): a0000059. https://doi.org/10.3687/jhis.a0000059

\section{Introduction}

Medical tourism is a phenomenon that refers to medical tourists travelling outside their residential area in order to obtain medical needs for a healthy life. This could include both domestic travel across the country and international travel across continents. Recent studies showed "India has emerged as one of the leaders in promoting medical tourism" (Ahmed, 2017). Many patients have been travelling across nations in recent years to receive the best quality medical treatments for various illnesses. Although rural people have been travelling to high tech urban areas for many decades, this dimension has been in the lighter shade of limelight compared to the recent years of international medical tourism.

India is the world's largest producer of generic medicine and there is a wide scope for medical value travel to India, both in conventional and alternative medical treatments (India, 2018). The Unani medicinal system has its origin in Greece and was initially conceptualised by Hippocrates (460-370) and the term referred to Perso-Arabic traditional practice. After which the Roman, Persian and Arab scholars contributed to the enrichment of the traditional Unani medical science. Galen (131-210) secured the foundation, thus allowing ${ }^{\star}$ the great Arab physician like Ibn Sina to construct a remarkable edifice. Soon after this bridge, it stretched its roots to a different geographical belt which influenced the development of Unani medicine.
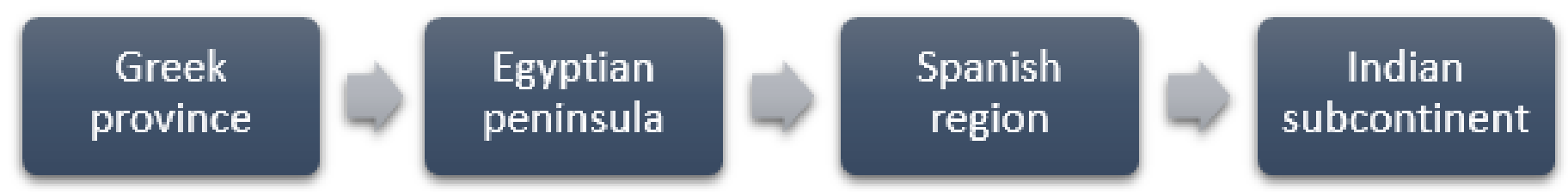

Figure 1. Expansion of Unani system across geographical belts (Author's source)

Figure 1 illustrates the geographical area through which the Unani medical system has expanded and bloomed, gaining popularity in various zones. Medical tourism has rehabilitated to traditional medical care therapies, herbal health care units and set a new benchmark for many countries across the globe. More medical tourists are travelling to India to seek the best alternative medical treatment. Apart from international medical travellers, it also opens the way for rural medical seekers to approach these systems. However, the rise in medical tourism for alternative medicine both domestically and internationally has widened up opportunities to enhance Indian comprehensive medicinal systems such as Ayurveda, Yoga, Unani, Siddha, and Homeopathy which are then abbreviated as AYUSH. AYUSH is a governmental Indian body educating, developing and conducting research in Indian traditional medicine. This body was created in the year
1995 and operated itself under the Ministry of Health and Family Welfare for a few years. Later it received its current name AYUSH in 2003, forming Ministry of AYUSH in 2014.

\section{Materials and Methodology}

\section{Overview of Unani system}

This system conscientiously deals with the state of the body (health) and its equilibrium (body function). According to Itrat (2016), Unani fully appreciates and understands the creation of man, his nature, his constitution and his relationship to the environment. In corresponding to Unani, health is classified into six components based on Scientific Proposition and Insights based on Wisdom (Hikmah). 


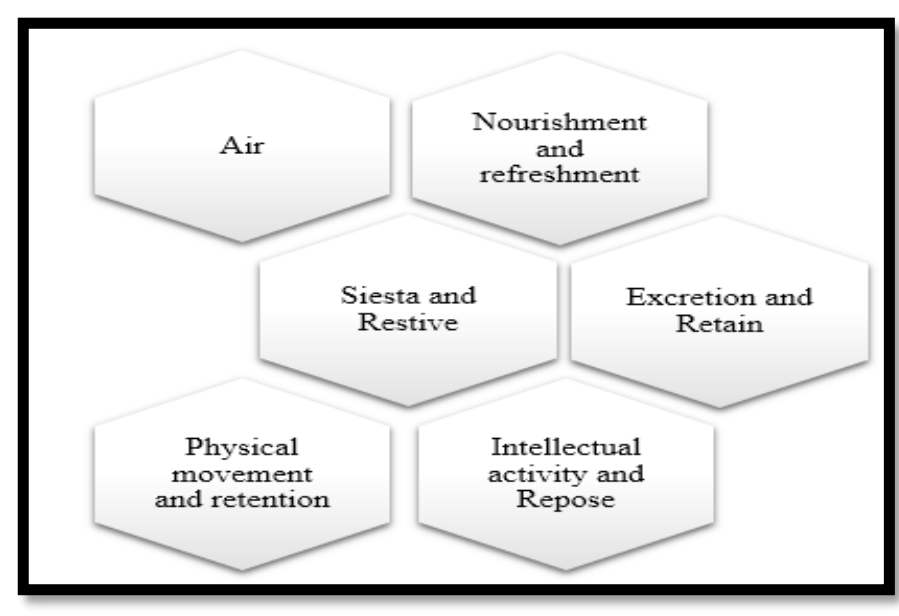

Figure 2. Components of Health in Unani system (Author's source)

Figure 2 explains the components of health according to Unani but this "theory is having an indirect partial similarity with the accepted definition of health as a state of physical, mental and social welfare" (Ahmed S., 2007). These components were derived after in-depth interviews with several Hakeem (Unani physician) in different parts of India.

\section{Emergence of Unani system in Indian Structure}

India is very popular for its oldest civilisation which dates to more than 5000 years along with its rich multifarious religious and cultural diversities. Indigenous Indian systems of medicine include Ayurveda, Yoga and Naturopathy, Unani, Siddha and Homeopathy (AYUSH), and "all these traditional healthcare systems are attracting national and international patients and generate tourism flows" (Naaz, 2016). "AYUSH refers to traditional and non-allopathic medical systems in India" (India, 2018).

After the growth of Unani medicine outreach, it stretched its roots deeply and established its integral source in a country filled with prosperous inherited biodiversity of flora and fauna which strengthens the system to research and explore the health problems in the recent generation and to obtain solutions with the power of ethnobotanical knowledge. An initiative taken by the Indian government is by promoting the traditional Indian healthcare systems and the "direction has been to mainstream AYUSH under National Health Mission (NHM)" (Naaz, 2016).

Unani medicine education in India is governed by the Central Council of Indian Medicine (Govt. of India) (Ahmed S., 2007). The central council for research in Unani medicine has eight regional research centres in "Chennai, Bhadrak, Patna, New Delhi, Mumbai, Kolkata, Aligarh and Srinagar" (Naaz, 2016). The regional institutes at Hyderabad and Chennai have been serving as a famous destination for medical tourism in respect to the treatment of vitiligo (skin ailment), joint diseases and other dermatological issues. The centre's clinical research on vitiligo in Hyderabad along with research studies in cosmeceutical effects of Unani drugs in Chennai has become a huge success by popularising Unani system and attracting not just domestic patients but also international medical tourists from "developed countries like USA and UK" (Naaz, 2016).

\section{Significance}

The rise in multiple medical facilities with well-equipped technology is a major factor for the growth of medical tourism. High-value services provided by the physicians create an ambience for medical tourists which is convenient and efficient for developing and strengthening a better doctor-patient relationship. Therefore, expanding the facilities worldwide by analysing the scope and determining the factors which inflate the choice of Unani treatment is beneficial and effective. Based on the elements that affect travel frequency among patients, it could make this specialised service industry improve the standard of providing appointments to its medical tourists in the prescribed given time. These aspects will bring sufficient enlargement and room for improvement in guest service. An amicable environment with better service staff and a good physician is of paramount importance. Furthermore, creating a record of Elevated Indian Physicians with a high level of medical training in the specialised field makes it a suitable estate for medical tourism.

\section{Islamic Approach towards Unani}

Unani is originally a Greco-Islamic Medical system, which inherited the innovation in the medicinal field by several Muslim physicians. One such specific Muslim scholar named Ibn Sina is popularly known as the "Prince of Physicians" (Ahmed, et al., 2011) by the Latin Scholars because of his magnificent work called Al-Qanoon fi al-Tibb (The Canon of Medicine). Furthermore, this renowned scholar produced many books and his fame chiefly rested on his two books namely The Canon of Medicine and Kitab al-Shifa. Due to his profound masterpiece, these books were considered as the two main encyclopaedias used by many countries in their scientific medical research.

The prime goal of health promotion in this holistic form of medicine (Unani) is only through the improvement of Tabiyat (Immunity) (Lone, et al., 2012). According to this form, anything in excess leads to harm, in reference to Hakeem al-Ruhawi who stated in his 'Adab el-Tibb' that any excess which appears is due to excessive eating and drinking or harmful use of these two (Irfan, 2011). However, Islam encourages Muslims to eat in moderation because of its beneficial factors. The following verse from Surah al-A'raf clearly explains that human is ordered not to commit excess in any way. As Allah SWT has instructed

"eat and drink and do not commit excesses; indeed, He does not love those who are excessive" (Translated, 2008)

Additionally, it improves self-control and instigates perfect changes in one's character, health and elevates the essence of spirituality. Thus, Unani medicine is referred to as the Halal version (Islam \& Chandrasekaran, 2013) of the Indian nutraceutical in relation to nourishment and pharmaceutical drugs. This is because of its natural composition which caters the needs of Halal conscious purchaser and those with a specific religious belief like Vegetarians.

Recent research by Jawad Alzeer, a Senior Research Scientist working on Halalopathy (Cochrane, 2019) reported that it is an old concept with new terminology. This approach was advanced by ancient Greeks which was then promulgated by Muslim polymath like Ibn Sina whose influence still prevails in countries like India, Pakistan as a traditional medicinal system called Unani. Consequently, this health therapy, which is Muslim friendly, can have a huge impact in Muslim majority countries like Malaysia, Indonesia and Brunei and has a potential market because of the rise in demand for Halal drugs among consumers. This will be a positive technique to increase Islamic economy and a way to serve not only Muslims but the whole society.

Scope of Unani medical tourism

"An increase in awareness levels on alternative medicine is inspiring tourists to embark on wellness trips or engage in wellness activities," says Mr Vijay (Karai, 2018). Perhaps it has become a wellness retreat among international and domestic medical tourists.

Basically, these three categories of patients who travel for medical tourism were the optimum outcome of the survey 
among Unani medical tourists;

1. Locals and foreigners who travel for medical treatment,

2. International patients travelling overseas for herbal treatment and leisure,

3. Emigrant or a guest worker in the host country/state.

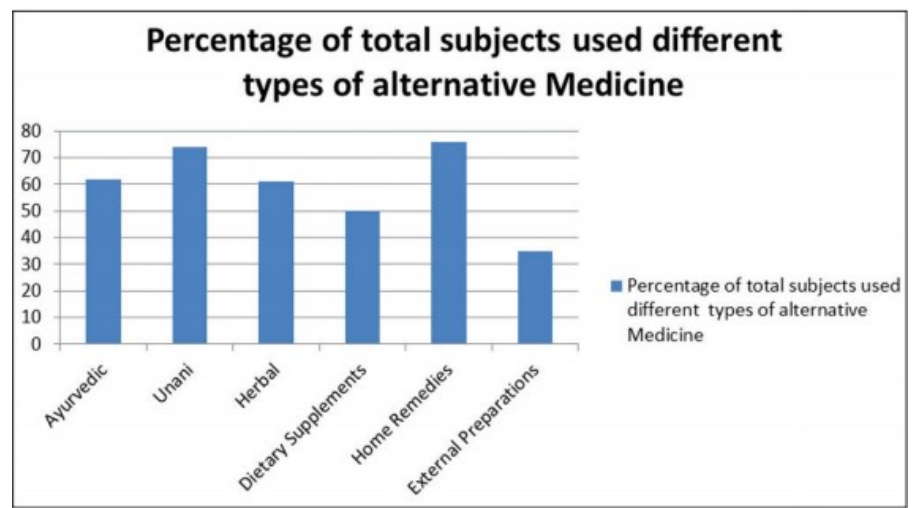

Figure 3. Preference of medical patients towards different healthcare therapies (Imran, et al. 2017)

Figure 3 shows the percentage in the usage of Unani has increased in the last few years among the domestic medical tourists and their preferences towards Unani healthcare therapy has inclined. Treatment in this therapy "includes prevention habits and management with the use of drugs from medicinal plants, herbs, minerals, metallic and animal origin" (Imran et al., 2017).

Therefore, the above analysis magnifies that home remedies have equally seen tremendous growth besides Unani. Indeed, it is one of the familiar and customary practices prevailing among people through ages because of the simple preparation made out of obtainable resources at home. Thus, the method requires no administered prescription or professional observation. Yet, the soaring rate of both Unani and home remedies has elevated because of their benefits and restoring properties.

\section{Executed Technique}

An exploratory study was carried out to understand the concept of Unani medical system and to investigate the factors that drive patients' demand and choice of this alternative medicinal system in India. Self-administered questionnaire was distributed to 200 domestic medical tourists across India with 50 international patients in various Unani dispensaries and Unani Govt College, Chennai. Most importantly, among 250 distributed questionnaires, only 172 respondents were used for further data analysis. Direct respondents' answers were collected from different dispensaries and clinics in South India and online questionnaires were circulated among the rest. One-to-one interviews were conducted with Unani medical practitioners to further enhance the quality of the research.

Table 1. Stakeholders in traditional healthcare system

\begin{tabular}{|l|c|}
\hline \multicolumn{1}{|c|}{ Stakeholders } & $\begin{array}{c}\text { No. of } \\
\text { respondents }\end{array}$ \\
\hline Indian medical tourists (North \& South) & 148 \\
International medical tourists & 7 \\
Government Unani Administrators & 3 \\
Public clinic Unani Hakeem & 4 \\
Private dispensaries Unani Hakeem & 6 \\
Unani Pharmaceutical companies (Admin) & 4 \\
\hline
\end{tabular}

\section{Data Analysis}

\section{Respondents' profile}

The participants shared their views on the Unani system, and opinion to spread the benefits of this medicinal method. They answered a 4-page survey sharing their experience of travelling to different cities for better treatments and the causes for seeking medical advice in another locality. Basic questions focused on the profile of the respondent and the remaining questions were focused mainly on factors, past medical history of Unani, sources who recommend travelling for this treatment and number of average travels per year domestically and internationally.
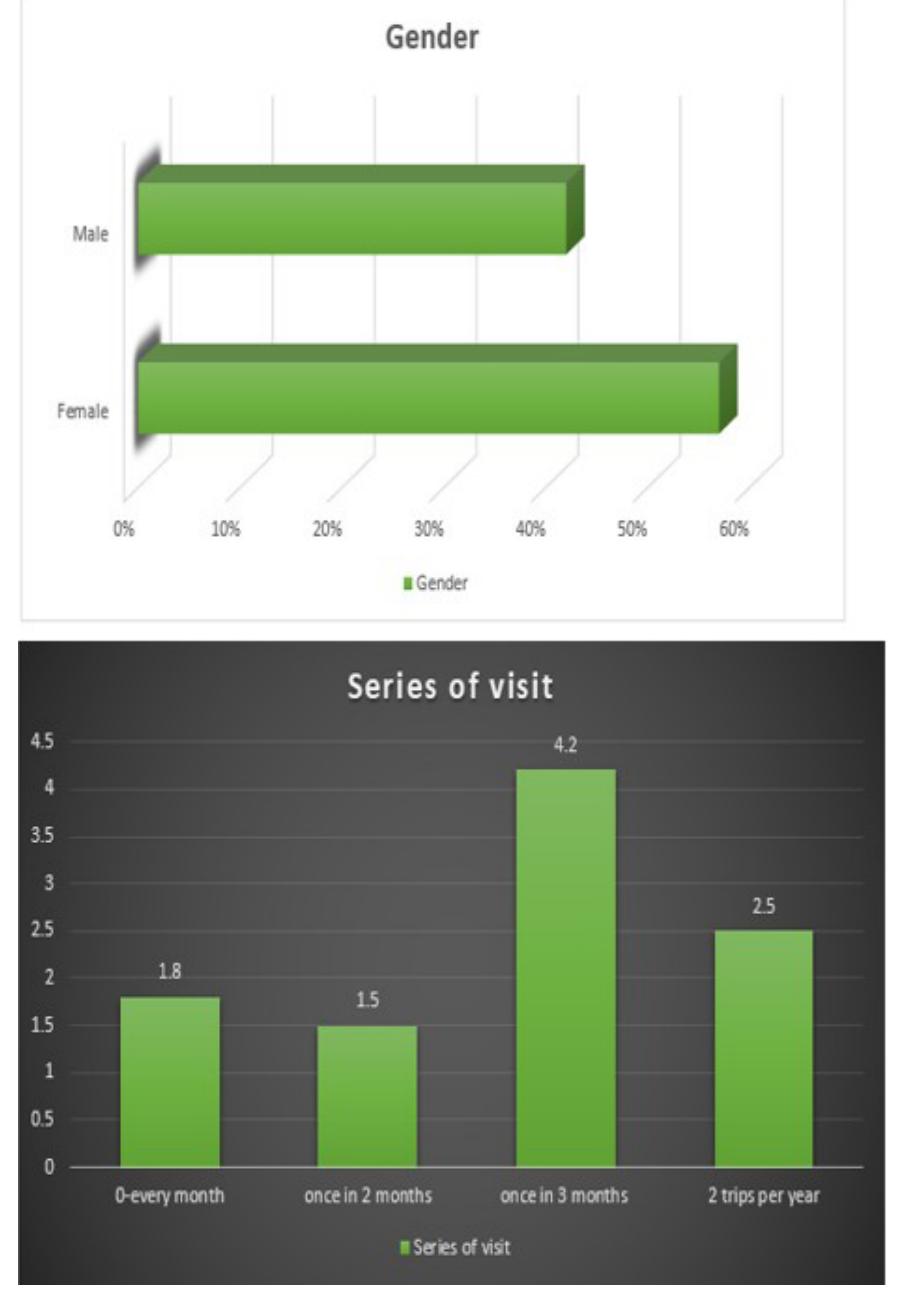

Figure 4. Gender and average travel per year

Figure 4 shows the number of female respondents was more compared to males as the health issues were more related to women such as fertility, thyroid, menopause, urinary tract conditions and PCOS. Male respondents were usually diagnosed with kidney bladder stones and liver ailments, high blood pressure, diabetes and heart health.

\section{Factors determining the choice of Unani medical system among medical tourists}

Realising the numerous benefits with the tremendous potentiality to treat diseases with no or comparatively minimal effect on the patients, Unani has gained fame across continents. This would have happened due to several inspiring factors; to list one such reason could be a Good Medical Physician's virtuous behaviour towards his/her medical patient who travels from a different region plays an essential role in the arena of medical tourism. 


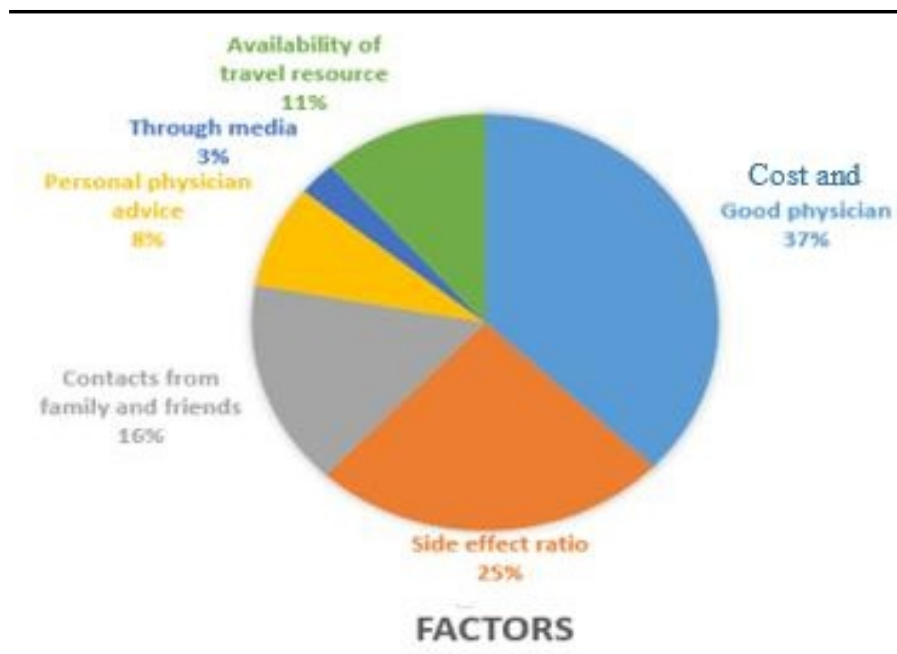

Figure 5. Factors determining the choice of Unani system among medical tourists

Based on the limitation of the respondents, the following results were evaluated based on their criteria and vital needs. Figure 5 explains the various factors that influence the choice of Unani. According to the respondents, these factors looked appealing when seeking medical treatment, above all these factors, the first "Core determinant was Cost and Good physician" for choosing this therapy. International respondents chose India because of its famous herbal heritage and the treatment is much cheaper than any other country.

The majority of the international medical tourists were from Malaysia and Singapore due to the Indian collaboration with these countries. Despite the fact of the limited sample size of respondents, the opinions and views delivered could not be constrained to the total population. Besides, their views were clearly demonstrated to comprehend the choice of Unani system and medical tourism.

Secondly, the well-known fact of side effect among the populous medical system is high, compared to this therapy. The profile of Unani drug is based on medicinal plants and herbs. Thus, making it consumable and inevitable for its consumers. Although it is known for its long-term medical treatment with no side effects, makes it more applicable for the medical tourists to travel for this eminent gem therapy.

\section{Elements affecting travel frequency:}

Figure 6 demonstrates the majority of patients prefer travelling once in every 3 months due to various reasons such as: 1. Health Condition; 2. Work; 3. Work off/Holiday; 4. Availability of Reliable Companion; 5. Affordability of Reasonable/Low-cost Travel requirements. The highest common reason for travel is health condition adjacent to the workplace scenario and a reliable companion to travel along. These are the prevalent factors based on the convenience of the medical tourists to establish a routine throughout the year. The rest of medical tourists travel based on their personal choice and availability of the above-mentioned resources.

\section{Unani developmental strategies}

Indian medical tourism developing strategies are based on Marketing Mix which includes 7 Ps (Dawn \& Pal, 2011). Therefore, this study attempts to present active operation on the elaborated factors which can enhance the advancement of Unani sector not only in India but also in Southeast Asian countries like Malaysia, Brunei, Indonesia and Singapore because of its Muslim friendly nature. The following Figure 7 intensifies the 7
Ps of marketing mix strategies which are presumed to strengthen Unani Medical Tourism. Particularly this system of medicine has deep historical roots with traditional healers and practitioners with inflated international mobility. Hence, perceiving substantial development of Unani system in other countries. The rationale behind alternative medicine system is the lack of key competitors in the corresponding fields (AYUSH). Consequently, it provides auxiliary sustainability for Indian medical tourism through economic development.

\section{Conclusion}

Tourism for Unani system will soon spread the charm in the medical tourism industry. Although setbacks prevail in this traditional system, Unani is still a strong force (Irfan, 2011) which continues to spread across and improves not just Muslims' well-being but additionally strengthens the doctor-patient relationship between non-Muslims. Another reason that will inspire medical tourists to travel would be its herbal benefits with affordable cost for the entire treatment. This will enhance the significant opportunity for herbal marketers across India for their valuable herbs and medicinal plants. Recent studies proved many physicians reported, "NCD treatment in other systems like Allopathy are very costly and the side effects of drugs are hazardous" (INDIA, 2018). Therefore, this increases the opportunity for various alternative medical therapies (AYUSH) in India. Unani's bond with Indian soil has been generated for many distinct eras. The breathtaking combination of vibrant landscapes, diverse cultures and herbal care makes it a perfect match for medical tourism. The cooperative pact between Ministry of AYUSH and Ministry of Tourism will ultimately result in a well-defined composition in terms of promoting Indian tourism and AYUSH together. Perhaps it can intensify the herbal health care practice and improve the standard of quality between both sectors by achieving universal recognition for Eminent Unani Healthcare for domestic and international medical seekers. Indian low-cost herbal healthcare therapy creates a great ambience for international and domestic medical cost-conscious tourists who get a perfect deal of both stunning tourisms with "high-quality alternative herbal treatment facility".

\section{Conflict of Interest} in this work.

The authors declare that there is no conflict of interest

\section{Acknowledgement}

The authors are thankful to the Ministry of Education of Malaysia for the funding through FRGS/1/2018/SSI03/ UIAM/02/3grant.

\section{References}

Ahmad, S. (2007). Unani medicine: Introduction and present status in India. The Internet Journal of Alternative Medicine, 6(1), 1-4.

Ahmed, N. F. (2017). Vellore - A hub for Medical Tourism. International Journal of Trend in Scientific Research and Development, 1(5), 493- 
Ahmad, W., Ahmad, G., Khan, N. A., et al. (2011). Ibn Sina: The prince of physicians. Hamdard Medicus, 54(4), 46-53.

Cochrane, P. (2019, March Monday). Halal, health and healing: Will halalopathy bring hope to patients?. Retrieved from https://www. middleeasteye.net/discover/halal-health-and-healingcan-halalopathy-appeal-bring-hope-muslims

Dawn, S.K., Pal, S. (2011). Medical tourism in India: issues, opportunities and designing strategies for growth and development. International Journal of Multidisciplinary Research, 1(3), 185-202.

Imran, M., Amir, M., Naqvi, H., Naaz, S., et al. (2017). The prevalence and patterns of usage of Ayurvedic, Unani and Home remedies in younger adults in rural North India. International Journal of Green Pharmacy, 11(2), 108-113.

India, T. H. (2018, December Thursday). National seminar on Unani on December 28-29. Retrieved from https://www.thehansindia. com/posts/index/Telangan a/2018-12 $27 / \mathrm{N}$ ation a l-s e minar-on-Unan i - on December-28-29/465281

India, T. T. (2018, September Monday). Immense scope for medical tourism between India, Netherlands. Retrieved from https:// timesofindia.indiatimes.com/india/immense scope-for-medical-tourism-between-india-netherlandsayushminister/articleshow/65662576.cms

Irfan, H. (2011, March Monday). Hikmat (Unani Medicine) - Islamic medicine is natural and simple. Retrieved from http://behalal. org / h e a l th / hi k m a t - un a n i - medicineislamic-medicine-is-natural-and-simple/

Islam, T., \& Chandrasekaran, U. (2013). Halal marketing: growing the pie. International Journal of Management Research and Review IJMRR, 3(12), 3938-3948.

Itrat, M. (2016). Research in Unani Medicine: Challenges and way forward. Alternative and Integrative Medicine, 5(1).

Karai, V. K. (2018, December Thursday). The Resurgence of Health and Wellness Tourism in India. Retrieved from https://www.entrepreneur.com/ article/324424

Lone, A. H., Ahmed, T., Anwar, M., Sofi, G., Imam, H., \& Habib, S. (2012). Perception of health promotion in Unani herbal medicine. Journal of Herbal Medicine, 2, 1-5.

Naaz, F. (2016). Medical tourism in India: Perspective of Unani Medicine. Journal of

\section{Abbreviation:}

AYUSH: Ayurveda, Yoga, Unani, Siddha, Homeopathy

NCD: Non-Communicable Disease

AYUSH $\quad$ K. (2019, January Thursday). Disease Burden, govt must train experts for clinical use. Retrieved from https:// w w w. news 18 .com/news/opinion/ a y u s h-can-help-india-tackle-growingdisease-burden-govt-must-train-experts-for-clinicaluse-1990189.html

Translated, M. A. (2008). Surah Al-A'raf. In A. (swt), The Qur'an (p. 512). Oxford, UK: Oxford University Press. 